Artigo de Revisão

\title{
Patogênese, sinais clínicos e patologia das doenças causadas por plantas hepatotóxicas em ruminantes $\mathrm{e}$ eqüinos no Brasil ${ }^{1}$
}

\author{
Julio Cesar A. Santos ${ }^{2}$, Franklin Riet-Correa ${ }^{3 *}$ Sara V.D. Simões ${ }^{3}$ e Cláudio \\ S.L. Barros ${ }^{4}$
}

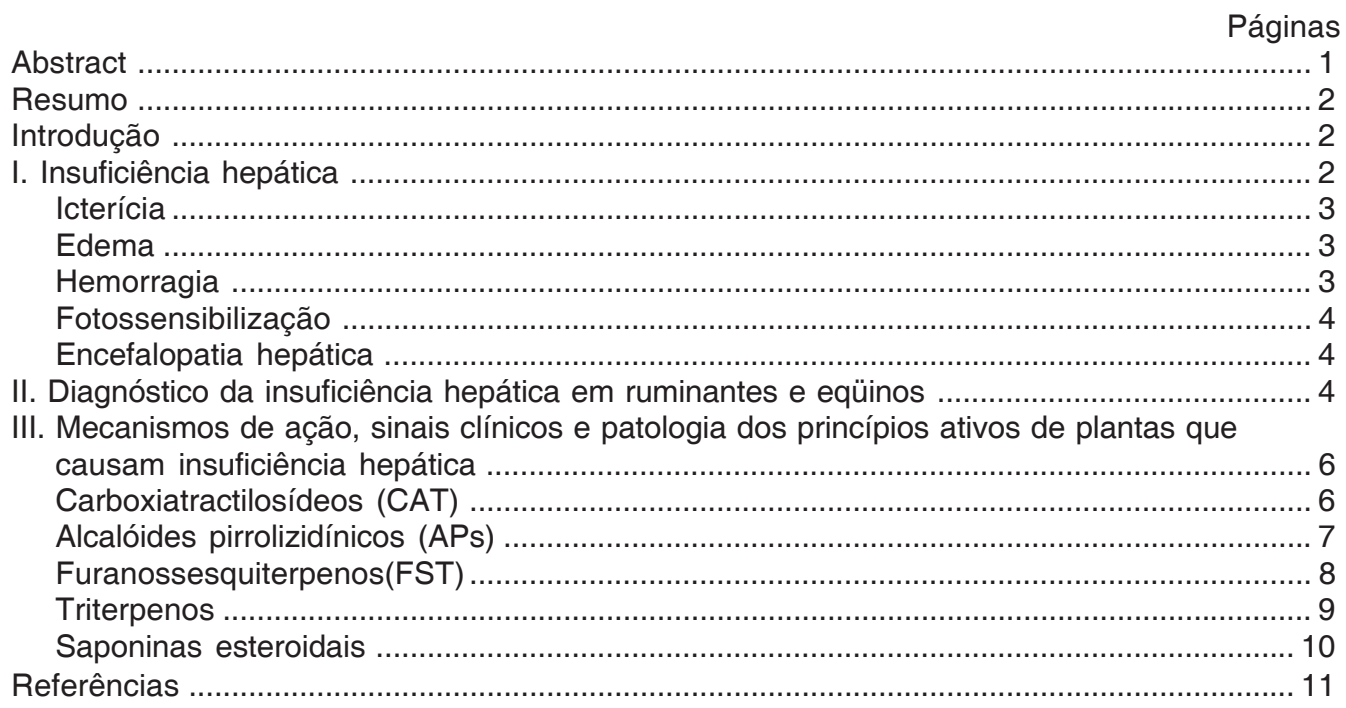

\begin{abstract}
Santos J.C.A., Riet-Correa F., Simões S.V.D. \& Barros C.S.L. 2008. [Pathogenesis, clinical signs and pathology of diseases caused by hepatotoxic plants in ruminants and horses in Brazil.] Patogênese, sinais clínicos e patologia das doenças causadas por plantas hepatotóxicas em ruminantes e eqüinos no Brasil. Pesquisa Veterinária Brasileira 28(1):1-14. Centro de Saúde e Tecnologia Rural, Universidade Federal de Campina Grande, Patos, PB 58700-000, Brazil. E-mail: franklin.riet@pq.cnpq.br

Plants causing hepatic lesions in ruminants and horses constitute one important group of poisonous plants in Brazil. These plants can be placed in three major groups: plants causing acute liver necrosis; plants causing liver fibrosis; and plants causing hepatogenous photosensitization. For some of these plants the toxic principles are known. Cestrum parqui and Xanthium cavanillesi that cause acute liver necrosis contain carboxyatractylosides. Senecio spp., Crotalaria spp., and Echium plantagineum that cause liver fibrosis contain pyrrolizidine alkaloids. As for the group of plants causing hepatogenous photosensibilization, Myoporum spp. contain furanosesquiterpenes, Lantana spp contain
\end{abstract}

\footnotetext{
${ }^{1}$ Recebido em 28 de junho de 2007.

Aceito para publicação em 8 de agosto de 2007.

2 Programa de Mestrado em Medicina Veterinária de Pequenos Ruminantes, Centro de Saúde e Tecnologia Rural (CSTR), Universidade Federal de Campina Grande (UFCG), Patos, PB 58700-000, Brasil. Email: asjcesar@yahoo.com.br
}

\footnotetext{
${ }^{3}$ Hospital Veterinário, CSTR, UFCG, Patos, PB 58700-000. *Autor para correspondência: franklin.riet@pq.cnpq.br

${ }^{4}$ Laboratório de Patologia Veterinária, Departamento de Patologia, Universidade Federal de Santa Maria, Avenida Roraima 100, Cidade Universitária, Bairro Camobi, 97105-900 Santa Maria, RS. E-mail: claudioslbarros@uol.com.br
} 
triterpenes, and Brachiaria spp. and Panicum spp. contain steroidal saponins. The clinical and pathologic features of the toxicosis caused by these phytotoxins, general mechanisms of production for the production of the clinical signs and the methods for diagnosis of hepatic failure in farm animals are reviewed.

INDEX TERMS: Hepatotoxic plants, liver failure, carboxyatractylosides, pyrrolizidine alkaloids, furanosesquiterpenes, triterpenes, steroidal saponins.

RESUMO.- Plantas que causam lesões hepáticas em ruminantes e eqüinos constituem um grupo importante de plantas tóxicas no Brasil. Em geral essas plantas podem ser divididas em três grandes grupos: plantas que causam necrose hepática aguda; plantas que causam fibrose hepática; e plantas que causam fotossensibilização. Em algumas dessas plantas os princípios tóxicos já foram identificados. Das plantas que causam necrose hepática aguda, os carboxiatractilosídeos estão presentes em Cestrum parqui e Xanthium cavanillesi. Os alcalóides pirrolizidínicos estão presentes nas plantas que causam fibrose hepática (Senecio spp., Echium plantagineum, Heliotropum spp. e Crotalaria spp.). Das plantas que causam fotossensibilização hepatógena são conhecidos os furanossesquiterpenos em Myoporum spp., triterpenos em Lantana spp., e saponinas esteroidais em Brachiaria spp. e Panicum spp. O quadro clínicopatológico dessas intoxicações e o mecanismo geral da insuficiência hepática, incluindo meios de diagnóstico, são descritos neste artigo de revisão.

TERMOS DE INDEXAÇÃO: Plantas hepatotóxicas, insuficiência hepática, carboxiatractilosídeos, alcalóides pirrolizidínicos, furanossesquiterpenos, triterpenos e saponinas esteroidais.

\section{INTRODUÇÃO}

No Brasil ocorrem pelo menos 35 espécies de plantas hepatotóxicas distribuídas em 16 gêneros e podem ser divididas em três grupos: plantas que causam necrose hepática aguda; plantas que causam fibrose hepática e plantas que causam fotossensibilização. Algumas delas têm princípio ativo conhecido, enquanto de outras não se conhecem as substâncias responsáveis pelo quadro clínicopatológico (Quadros 1-3). O objetivo deste trabaIho foi revisar os mecanismos de ação das plantas hepatotóxicas que ocorrem no Brasil. Adicionalmente, para facilitar o reconhecimento dessas intoxicações pelos veterinários de campo, se inclui uma seção sobre sinais clínicos e patologia da insuficiência hepática.

\section{INSUFICIÊNCIA HEPÁTICA}

O fígado é o responsável pelos processos de síntese, excreção e catabolismo (Kelly 1993). As substâncias absorvidas pelo intestino têm seu primeiro contato no organismo com o fígado, que numa posição estratégica, impede a exposição do restante do organismo à ação de toxinas. Os sistemas enzimáticos de detoxificação hepática, como a citocromo P-450, atuam de forma rápida e têm ampla especificidade, dando ao animal a capacidade de suportar uma grande variedade de desafios causados por toxinas naturais e sintéticas (Cheeke 1994).

A insuficiência hepática ocorre somente em lesões difusas quando há comprometimento de $75 \%$ do parênquima hepático, como ocorre nas intoxicações, e não ocorre em lesões focais ou multifocais como, por ex., abscessos ou cistos. Os principais sinais clínicos causados pela insuficiência hepática são icterícia, edema, hemorragias, fotossensibilização e encefalopatia hepática. Outros sinais clínicos da insuficiência hepática aguda incluem si-

Quadro 1. Plantas que causam necrose hepática aguda em ruminantes e eqüinos no Brasil

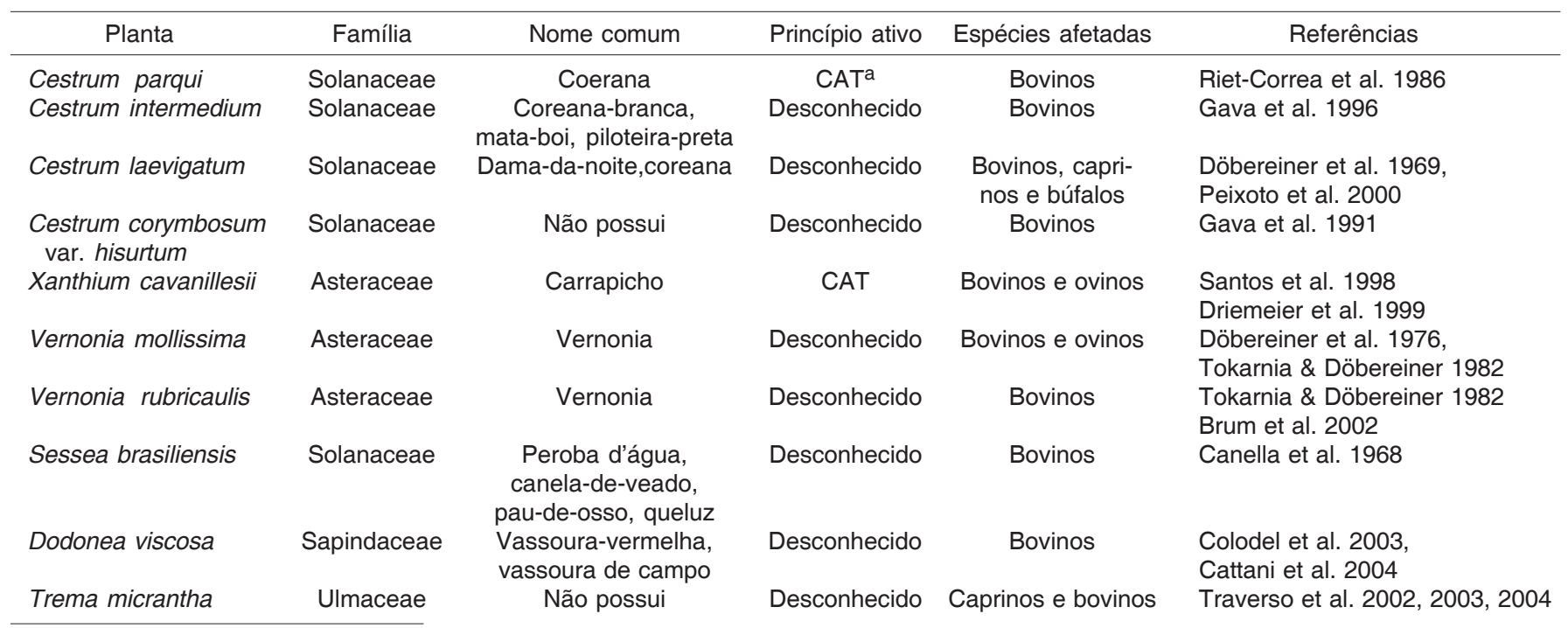

a Carboxiatractilosídeo. 
Quadro 2. Plantas que causam fibrose hepática em ruminantes e eqüinos no Brasil

\begin{tabular}{|c|c|c|c|c|c|}
\hline Planta & Família & Nome comum & Princípio ativo & Espécies afetadas & Referências \\
\hline Crotalaria retusa & $\begin{array}{l}\text { Fabaceae } \\
\text { (Leguminosae) }\end{array}$ & $\begin{array}{l}\text { Guizo de cascavel, } \\
\text { chocalho,xique-xique }\end{array}$ & $\mathrm{AP}^{\mathrm{a}}$ & $\begin{array}{l}\text { Bovinos, eqüinos } \\
\text { e ovinos }\end{array}$ & $\begin{array}{l}\text { Dantas et al. 2004, } \\
\text { Nobre et. al. 2004a,b, } 2005\end{array}$ \\
\hline $\begin{array}{l}\text { C. juncea } \\
\text { C. retusa }\end{array}$ & $\begin{array}{l}\text { Fabaceae } \\
\text { (Leguminosae) }\end{array}$ & Idem & AP & & Nobre et al. 1994 \\
\hline $\begin{array}{l}\text { Senecio brasiliensis } \\
\text { S. selloi } \\
\text { S. cisplatinus } \\
\text { S. heterotrichus } \\
\text { S. leptolobus } \\
\text { S. oxyphyllus } \\
\text { S. tweediei }\end{array}$ & Asteraceae & $\begin{array}{l}\text { Maria-mole, flor das } \\
\text { almas, tasneirinha }\end{array}$ & AP & & $\begin{array}{l}\text { Barros et. al. 1987, 1992, } \\
\text { Gava \& Barros 1997, } \\
\text { Méndez et al. 1987, 1993, } \\
\text { llha et al. 2001, } \\
\text { Karan et al } 2004\end{array}$ \\
\hline $\begin{array}{l}\text { Echium plantagineum } \\
\text { Tephrosia cinerea }\end{array}$ & $\begin{array}{c}\text { Borraginaceae } \\
\text { Fabaceae } \\
\text { (Leguminosae) }\end{array}$ & $\begin{array}{c}\text { Flor-roxa, língua de vaca } \\
\text { Falso-anil }\end{array}$ & $\begin{array}{c}\text { AP } \\
\text { Desconhecido }\end{array}$ & $\begin{array}{l}\text { Bovinos } \\
\text { Ovinos }\end{array}$ & $\begin{array}{l}\text { Méndez et. al. } 1985 . \\
\text { Santos et al. } 2007\end{array}$ \\
\hline
\end{tabular}

Quadro 3. Plantas que causam fotossensibilização hepatógena em ruminantes e eqüinos no Brasil

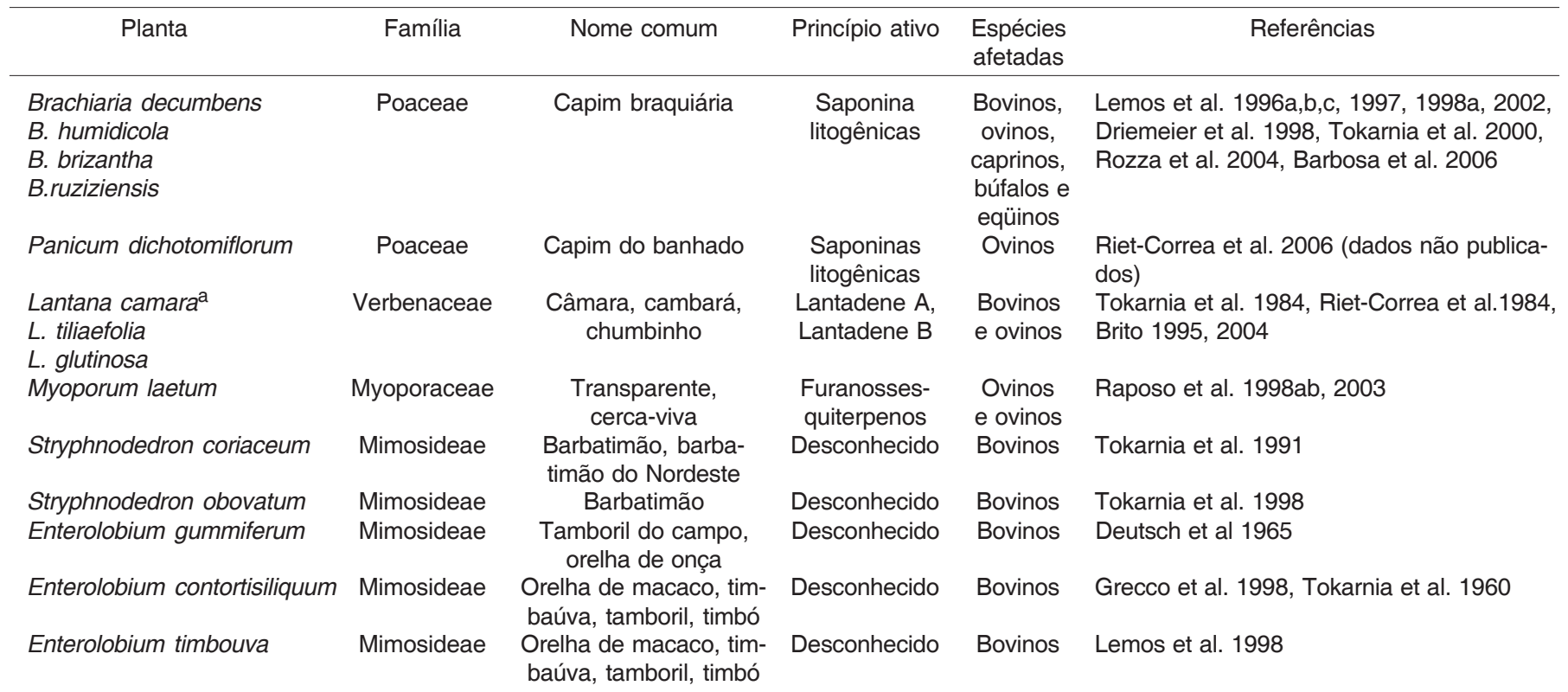

Também pode causar fibrose

nais de dor (escoicear o abdômen, gemidos, dorso arqueado), constipação com fezes secas ocasionalmente recobertas por muco ou estrias de sangue e hipotonia ou atonia ruminal.

Icterícia. A colestase é uma falha hepática na excreção e secreção de pigmentos, ácidos biliares e sais biliares. Esse fenômeno produz uma síndrome clínica conhecida como icterícia que consiste no amarelamento dos tecidos pela deposição pigmentos biliares. A intensidade dessa coloração depende da intensidade (quantidade de pigmento biliar que está sendo retido) e a duração da colestase. Quando a colestase dura vários dias, os tecidos equilibram seus níveis de pigmentos biliares com os do plasma e a icterícia é acentuada (Kelly 1993, Kelly 2002).

Edema. Os edemas hipoproteinêmicos podem ocorrer na insuficiência hepática em decorrência da falha na síntese de albumina e outras proteínas do plasma pelo fígado.

O edema em ruminantes e eqüinos ocorre principalmente nas partes de declive (regiões ventrais) do tecido subcutâneo, mas também em cavidades orgânicas, no mesentério e parede de algumas vísceras. Nas doenças que causam fibrose, como intoxicação por Senecio spp. em bovinos a hipertensão portal pela fibrose hepática pode ter participação na gênese do edema (Barros et al. 1992). Em geral, edema pode ocorrer por alterações de permeabilidade vascular, falha circulatória (aumento da pressão hidrostática) e hipoproteinemia por insuficiência renal, parasitoses ou má-nutrição; o clínico deverá levar em consideração essas possibilidades, ao realizar no diagnóstico diferencial de insuficiência hepática (Kelly 1993, Kelly 2002).

Hemorragia. A lesão aguda grave do fígado pode causar hemorragias. Durante uma fase de necrose, uma grande proporção de sangue do animal é posta em contato com uma grande proporção de tecido lesado e endotélio 
vascular. Isto faz disparar a cascata da coagulação que por sua vez iniciará também o fenômeno de fibrinólise compensatória. O resultado, se esta seqüência de eventos for rápida, é o consumo dos fatores de coagulação. A depleção nesse caso é mais profunda já que esses fatores em sua maioria são sintetizados pelo fígado. Os animais com esse quadro clínico patológico terminam por apresentar diáteses hemorrágicas observadas, principalmente, na necropsia sob a forma de petéquias e equimoses (Kelly 1993, Kelly 2002, Cullen 2007).

Fotossensibilização. A falta de eliminação de filoeritrina pelo sangue portal em animais com insuficiência hepática tem especial significado em herbívoros. Este pigmento é produzido no trato digestivo pela degradação da clorofila e excretado na bile. Quando há obstrução biliar a filoelitrina não é eliminada e se acumula nos tecidos. Em áreas de pele despigmentadas e expostas à luz solar essa substância, que é fotodinâmica, reage com a luz ultravioleta causando dermatite, com dano vascular e epidérmico, condição conhecida como fotossensibilização secundária ou hepatógena. Como a excreção de filoeritrina segue os mesmos passos da eliminação dos pigmentos biliares é comum, porém não obrigatório, observar-se icterícia associada à fotossensibilização secundária. Uma elevação dos valores de bilirrubina e/ou ácidos biliares é observada na fotossensibilização hepatógena (Kelly 1993, Kelly 2002).

Encefalopatia hepática. Os sinais clínicos neurológicos da encefalopatia hepática resultam do acúmulo na corrente sangüínea, no líquido cefalorraquidiano e no encéfalo de substâncias como a amônia, ácidos graxos de cadeias curtas e mercaptanos, além de alterações nas concentrações de neurotransmissores. Normalmente, substâncias tóxicas são eliminadas quando de sua passagem pelo fígado, o que não ocorre quando há lesão hepática difusa grave com insuficiência hepática; em conseqüência essas substâncias podem chegar ao encéfalo e como falsos neurotransmissores causar vários sinais clínicos neurológicos (Kelly 2002). A amônia é considerada como a principal substância envolvida na patogênese da encefalopatia hepática (Kellerman et al. 2005, Radostits et al. 2002). A elevada quantidade de amônia no sangue leva ao acúmulo dessa susbstância no encéfalo, onde ela reage com o ácido $\alpha$-cetoglutárico para formar a glutamina. A depleção do $\alpha$-cetoglutarato, que é um intermediário do ciclo do acido cítrico, prejudica a formação do ATP, conduzindo a uma diminuição do ATP para conduzir o metabolismo cerebral (Cheeke 1998). A base morfológica desses sinais neurológicos é uma degeneração esponjosa no sistema nervoso central causada pela hiperamonemia. Estão aumentados os níveis de amônia no sangue e de glutamina no líquido cefalorraquidiano (Hooper et al. 1974, Hooper et al. 1975). A degeneração esponjosa (status spongiosus), que ocorre por um edema intramielínico, é mais pronunciada na substância branca do mesencéfalo, base do encéfalo, nos pedúnculos cerebelares e na junção entre substância branca e cinzenta (llha et al. 2001, Mendez et al. 1987, Barros et al. 1987, Barros et al. 1992).
É provável que existam diferenças entre as espécies na patogênese e manifestação da encefalopatia hepática. A mielinopatia espongiforme que ocorre na maioria das espécies aparentemente não ocorre no homem e no cavalo. Ao invés disso, nessas espécies, observamos um aumento no tamanho dos astrócitos, que neste caso são denominados de astrócitos Alzheimer tipo II (Nobre et al. 2004a, Pilati \& Barros 2007).

\section{DIAGNÓSTICO DA INSUFICIÊNCIA HEPÁTICA EM RUMINANTES E EQÜINOS}

Os sinais clínicos de insuficiência hepática são variados e isso pode representar uma dificuldade na interpretação e confirmação do diagnóstico de insuficiência hepática pelo veterinário de campo, pois é necessária a utilização de métodos complementares como a biópsia e avaliação das enzimas hepáticas.

A biopsia hepática é usada extensamente como um método de diagnóstico de lesões hepáticas difusas em trabalhos experimentais e tem sido usada no diagnóstico de casos subclínicos da intoxicação por Senecio spp. em bovinos (Barros et al. 2007). O método pode ser repetido várias vezes no mesmo animal sem efeitos negativos. Esse método pode ser aplicado apenas ao diagnóstico de lesões hepáticas difusas. Para biópsia hepática de lesões focais é necessária a orientação por ultra-sonografia (Radostits et al. 2002) o que aumenta a eficiência do método, mas diminui sua praticidade. As amostras devem medir no mínimo $7 \mathrm{~mm}$, de modo a conter tecido suficiente para um exame histológico adequado ou para análise química, como por exemplo de cobre (Kelly 2002).

As provas bioquímicas realizadas no soro sanguíneo dos animais domésticos representam um valioso apoio ao diagnóstico clínico das enfermidades do fígado; esses exames incluem baterias de provas referidas como testes de função hepática (Souza et al. 2004). Os resultados e a interpretação de tais testes dependem da natureza da lesão, duração e intensidade da doença, além das variações entre as espécies (Radostits et al. 2002).

Para avaliar a função hepática são indicados vários parâmetros; todos eles apresentam restrições, pois existe interdependência do fígado com outros órgãos (Morais et al. 2000). Os testes de função hepática incluem os que medem o transporte (secreção, conjugação e excreção) tais como bilirrubina (BIL) e ácidos biliares, a atividade enzimática no soro para detectar necrose, colestase e carcinomas, e os bioquímicos que avaliam a capacidade hepática de metabolização de nutrientes como carboidratos, lipídios e proteínas (Kramer e Hoffman 1997). Há várias enzimas intracelulares que se encontram em grandes concentrações nos hepatócitos. Quando seus níveis estão aumentados no sangue, é possível que esteja ocorrendo uma doença hepática ativa. As enzimas específicas do fígado diferem entre as espécies (Kelly 2002). Em bovinos adultos, gama-glutamiltransferase (GGT), fosfatase alcalina (FA), sorbitol-desidrogenase (SDH) e aspartatoaminotranferase (AST) são as mais úteis na identificação 
de doença hepática crônica. A SDH tem meia-vida curta no soro e sua atividade pode não estar elevada no soro em bovinos com doença hepática crônica. Nos estágios iniciais de doença hepática nos bovinos, a SDH é o teste mais eficiente e sensível. Nos estágios tardios, quando os testes de excreção biliar são mais aplicáveis, a determinação da bilirrubina sérica e os testes da bromossulftaleína são indicados. Nenhum desses testes é indicado para avaliar a função hepática de bezerros com menos de seis meses de idade; nesses casos é indicada para a biópsia hepática (Radostits et al. 2002).

Em eqüinos é indicada a avaliação dos ácidos biliares séricos totais, GGT e a biópsia hepática. Esses exames são úteis para identificação de diferentes tipos de doenças hepáticas nessa espécie. Nos estágios iniciais de disfunção hepática, a SDH é a indicada. A concentração de amônia plasmática pode-se encontrar significativamente elevada em comparação com eqüinos clinicamente normais, mas nem sempre é acompanhada por declínio na concentração de uréia plasmática. Uma queda na concentração de glicose plasmática é um mau prognóstico (Radostits et al. 2002).

O proteinograma é um exame indicado para a determinação da causa do edema. A insuficiência hepática resulta na falha da síntese de aminoácidos e proteínas, principalmente albumina; essa condição manifesta-se por emagrecimento e queda dos níveis das proteínas plasmáticas e, se suficientemente acentuada resulta em edema por decréscimo na pressão osmótica do plasma (Kelly 1993, Kelly 2002, Radostits et al. 2002).

A AST, conhecida também como transaminase glutâmico-oxalacética, é encontrada principalmente no fígado, nos eritrócitos e nos músculos esquelético e cardíaco. Normalmente é utilizada para avaliar lesão muscular em conjunto com creatina fosfocinase (CK) e lactato desidrogenase. Em ruminantes e eqüinos, devido a suas altas concentrações no fígado, é usada também para investigar doenças hepáticas (Kerr 2003), porém não é específica para o diagnóstico das hepatopatias (Radostits et al. 2002).

A GGT ocorre em todas as células com exceção das células musculares. Sua atividade é alta nos rins e no fígado, mas somente a GGT de origem hepática é encontrada no plasma, uma vez que a de origem renal é excretada na urina. O aumento da atividade dessa enzima ocorre, em todas as espécies examinadas, após colestase. A avaliação da GGT é indicada para o diagnóstico de colestase em ruminantes, por ser uma enzima originária das membranas dos canalículos e ductos biliares; o aumento da atividade dessa enzima está relacionado exclusivamente a colestase intra e extra-hepática e com proliferação de ductos biliares (Seawright et al. 1978). A GGT normalmente está restrita ao retículo endoplasmático liso, onde o sistema de oxidase mista é ativo. Os alcalóides pirrolizidínicos (AP) são ativados por este sistema causando lesões nos hepatócitos e liberação da GGT no soro (Curran et al. 1996). Quando for observa- do aumento nas enzimas, principalmente GGT deve-se fazer uma biopsia para avaliar a intensidade das lesões hepáticas.

A bilirrubina existe no soro sob duas formas: indireta ou não conjugada (hemobilirrubina) e direta ou conjugada (diglicuronato de bilirrubina); a soma das duas representa a bilirrubina total. O exame laboratorial do soro, visando à detecção de quantidades relativas de bilirrubina nãoconjugada e bilirrubina conjugada é essencial na determinação da causa da icterícia (Coles 1984, Smith 2002). Nas lesões hepáticas ou do trato biliar ocorre queda na excreção de BIL. Nas anemias hemolíticas ocorre aumento na produção de BIL. O acúmulo de BIL conjugada resulta em icterícia mais pronunciada que a causada por quantidade similar de BIL não conjugada, daí o resultado de que a icterícia mais pronunciada é geralmente observada nos casos de lesão obstrutiva biliar ou hepática. Nas anemias hemolíticas estão elevados os níveis de BIL nãoconjugada (Smith 2002).

A ALT, também conhecida como transaminaseglutâmico-pirúvica, ocorre em tecidos com metabolismo de aminoácidos ativo, como o fígado, rins, músculo esquelético e miocárdio. Em geral, a ALT pode ser considerada uma enzima indicadora de lesão hepática em primatas, cães, gatos, coelhos e ratos. No entanto, em suínos, eqüinos, bovinos, ovinos e caprinos, ALT tem pouco valor diagnóstico, uma vez que é encontrada em concentrações muito baixas no fígado dessas espécies (Scheffer \& González 2006).

A FA é amplamente distribuída no organismo (osteoblastos, mucosa intestinal, células renais, hepáticas e placentárias) de modo que, isolada, não é específica para nenhum órgão. Nos distúrbios hepáticos detecta-se o aumento de sua atividade no soro em decorrência de colestase por obstrução dos canalículos biliares (Kaneko 1989), mas nem toda hepatopatia significativa causa um aumento de FA (Scheffer \& González 2006). Essa enzima, apesar de não ser específica para lesão hepática, aumenta nos casos de danos hepáticos em decorrência de sua liberação na superfície sinusoidal dos hepatócitos e na regurgitação das isoenzimas biliares nos casos de colestase. Nas intoxicações por AP ocorrem as duas situações (Craig et al. 1992).

A determinação da atividade sérica da enzima glutamato desidrogenase (GLDH) é indicada para avaliar necrose hepática em ovinos, caprinos e bovinos. A GLDH também pode estar elevada no período do parto e associada a obstruções dos ductos biliares. Em geral a elevação da atividade sérica de GLDH ocorre mais rapidamente do que a à da GGT, mas retorna aos níveis normais também mais rapidamente (Tennant 1997).

A arginase encontra-se elevada no soro após uma lesão aguda do fígado, retornado aos valores normais mais rapidamente do que a ALT e AST. Em hepatites necrosantes crônicas os níveis de arginase podem se manter elevados, indicando mau prognóstico. A elevação da atividade sérica da arginase já foi demonstrada em várias 
espécies, mas pode ter valor diagnóstico em eqüinos, bovinos, ovinos, caprinos e cães (Tennant 1997).

A SDH é uma enzima com meia vida de no máximo 24-48 horas com pico logo após a ocorrência lesão e retornando aos valores normais em cerca de três dias. Por isso deve ser analisada no início da doença (Meyer et al. 1995). É particularmente indicada em eqüinos para diagnosticar lesão hepatocelular aguda, mas também pode ser utilizada em ruminantes, em lugar da GLDH. É uma enzima seletiva como indicador de função hepática em ovinos e bovinos (Radostits et al. 2002). A SDH e a arginase são enzimas mais específicas de função hepática em ruminantes, porém, é uma análise mais complicada e de alto custo.

A concentração de ácidos biliares séricos é descrita como um indicador sensível e específico de doença hepatobiliar no homem e nos animais. Em bovinos os ácidos biliares totais são indicadores mais específicos e sensíveis de uma variedade de doenças hepáticas, correlacionando-se significativamente com o grau de lesão, quando comparados com outros testes da função hepática. Em eqüinos, as concentrações de ácidos biliares séricos totais também são indicadores sensíveis de várias doenças hepáticas, sendo mais úteis quando combinadas com outros testes de função hepática (Radostits et al. 2002). O colesterol é de importância diagnóstica apenas em pequenos animais. Em herbívoros a concentração é normalmente muito baixa e um aumento não tem associação específica com qualquer quadro (Kerr 2003). Elevações no colesterol sérico são observadas na obstrução biliar extra-hepática (Meyer et al. 1995). A depuração de substâncias químicas (corantes como a bromossulftaleína ou a indocianina verde) pode fornecer importantes indícios de falha hepática, no entanto, seu uso é limitado em função do alto custo e do tempo necessário para a sua utilização (Kelly 2002).

\section{MECANISMOS DE AÇÃO, SINAIS CLÍNICOS E PATOLOGIA DOS PRINCÍPIOS ATIVOS DE PLANTAS QUE CAUSAM INSUFICIÊNCIA HEPÁTICA}

Carboxiatractilosídeos (CAT). Glicosídeos são éteres que contém uma metade formada por carboidratos e outra metade formada por não-carboidratos, unidas a um grupo éter. Os CAT são glicosídeos triterpenóides responsáveis pelo quadro de insuficiência hepática aguda em ruminantes. São encontrados em Cestrum parqui e Xanthium cavanillesii (Cheeke 1998). Em outras plantas que causam o mesmo tipo de lesão ainda não se conhecem os princípios tóxicos. Os CAT causam inibição da respiração das mitocôndrias e da síntese de ATP (Vignais et al. 1962), inibindo o transporte de ADP/ATP através da membrana da mitocôndria e alterando o processo de fosforilação oxidativa pelo bloqueio da translocação da adenina nucleotídeo nessa organela (Luciani et al. 1978).

Os sinais clínicos na intoxicação por CAT em bovinos e ovinos são agudos e consistem de apatia, anorexia, parada dos movimentos ruminais, dores abdominais, tenesmo retal com discreto prolapso de reto, sudorese, desidratação progressiva com retração dos globos oculares e sinais nervosos caracterizados por incoordenação motora, tremores musculares generalizados e agressividade. Os animais investem à aproximação de pessoas, porém caem ao solo com facilidade manifestando sinais de fraqueza, às vezes apoiando a cabeça em obstáculos. $\mathrm{Na}$ fase terminal apresentam cegueira, decúbito lateral com movimentos de pedalagem, coma e morte. O curso clínico pode ser superagudo ou agudo, sendo, na maioria dos casos de 1-3 dias (Riet-Correa et al. 1986, Driemeier et al. 1999, Loretti et al. 1999, Colodel et al. 2000).

O fígado pode estar aumentado de volume e com os bordos arredondados e as lesões podem variar em intensidade, de moderada a acentuada. Na superfície de corte podem ser encontradas áreas vermelho-escuras alternadas com áreas claras amareladas marcando distintamente o padrão lobular (acentuação do padrão lobular). As áreas escuras correspondem à necrose e hemorragia $e$ estão deprimidas em relação o restante do parênquima. Hemorragias focais podem ocorrer distribuídas aleatoriamente na superfície natural e de corte. Nos casos mais agudos o fígado pode estar aumentado de tamanho, congesto, mas sem acentuação do padrão lobular. A vesícula biliar pode estar distendida e com edema gelatinoso e translúcido da parede. Edema pode também ocorrer no mesentério, nos ligamentos da curvatura maior e menor do abomaso e na região perirrenal. Observa-se hidropericárdio, discreto edema e acentuado avermelhamento difuso das dobras da mucosa do abomaso e hemorragias múltiplas, sob a forma de petéquias, equimoses e sufusões, disseminadas no tecido subcutâneo, omento, mediastino, serosas, mucosas da vesícula biliar, bexiga, timo, linfonodos, úbere, epicárdio e endocárdio. No reto há pequena quantidade de fezes ressequidas, em forma de esferas e recobertas por muco e estrias de sangue coagulado. No rúmen e no retículo podem ser encontrados folhas ou frutos das plantas (Riet-Correa et al. 1986, Driemeier et al. 1999, Loretti et al. 1999, Colodel et al. 2000).

A principal lesão microscópica ocorre, também, no fígado de forma difusa e consiste em acentuada necrose coagulativa hepatocelular centrolobular acompanhada de congestão e hemorragias. Alterações degenerativas, como vacuolização de hepatócitos e glóbulos eosinofílicos, podem ser observadas principalmente próximas ao limite da área com necrose e hepatócitos morfologicamente normais. Os hepatócitos necróticos estão dissociados, diminuídos de tamanho, com citoplasma fortemente eosinofílico, condensado, homogêneo e refringente e com núcleos picnóticos, cariorréticos ou ausentes. Em alguns casos necrose massiva pode ser observada, com a lesão se estendendo aos hepatócitos periportais. Pequena quantidade de neutrófilos e de células mononucleares podem preencher a luz de veias centrolobulares e sublobulares e entremear-se nos extensos focos necróticos. A lesão 
centrolobular pode atingir cerca de dois terços do lóbulo hepático a partir da veia central. A zona intermediária do lóbulo pode apresentar, além da necrose, estreita faixa de hepatócitos muitos tumefeitos, vesiculares ou espumosos, com núcleo muitas vezes picnótico, com evolução para cariólise. Hepatócitos da zona periportal podem estar tumefeitos, com citoplasma granular ou microvesicular. Pode ser observado, também, ativação das células de Kupffer e tumefação das células endoteliais dos sinusóides (Driemeier et al. 1999, Loretti et al. 1999, Colodel et al. 2000). Geralmente não são constatadas alterações microscópicas no sistema nervoso central, apesar da gravidade das lesões encontradas no fígado (Driemeier et al. 1999). Outros autores relatam lesões microscópicas no sistema nervoso na intoxicação por Xanthium spp incluindo cromatólise associada à astrogliose e espongiose no cérebro e mesencéfalo, indicando degeneração neuronal e edema. Menciona-se ainda degeneração neuronal isquêmica, congestão na maior parte do cérebro e hemorragias focais no cérebro e cerebelo (Witte et al. 1990, Santos et al. 1998).

Lesões ultra-estruturais descritas na intoxicação de ovinos por Xanthium cavanillesii consistem de dilatação dos espaços de Disse que se encontram preenchidos por hepatócitos necróticos e neutrófilos. Adicionalmente pode ocorrer lesão acentuada das células endoteliais dos sinusoides, ruptura de segmentos da parede desses capilares com o surgimento de áreas de descontinuidade acompanhadas de agregação plaquetária. Nos hepatócitos observam-se acentuada dilatação das cisternas do retículo endoplasmático, tumefação de mitocôndrias, desaparecimento de grânulos de glicogênio e picnose nuclear (Colodel et al. 2000).

Alcaloides pirrolizidínicos (AP). Alcalóides pirrolizidínicos são compostos que contêm nitrogênio, usualmente no anel heterocíclico e são geralmente substâncias básicas. O núcleo dos AP contem 2-5 anéis. São responsáveis pela toxicidade de vários grupos de plantas (Cheeke 1998). A maioria é constituída por ésteres de dois aminoácidos, retronecina e heliotridina, e ocorrem em três grupos: monoésteres, não-cíclicos (abertos) e diésteres cíclicos em ordem crescente de toxicidade. Para serem hepatotóxicos necessitam de ligação dupla 1,2 no núcleo pirrolizidínico e uma ramificação no grupamento éster. $\mathrm{N}$-óxidos de AP podem ser convertidos no trato alimentar em base nitrogenada livre do tóxico. Uma lista completa dos AP seria muito longa, pois só o Echium plantagineum contém pelo menos 10 tipos tóxicos para os animais de fazenda. Alguns destes alcalóides têm também efeito sobre os pulmões, como a monocrotalina, ou sobre o rim (Radostits et al. 2002). Os AP causam danos irreversíveis ao fígado, alguns deles inclusive são carcinogênicos (Cheeke 1994).

As principais plantas tóxicas que contém AP são as da família Boraginaceae (todos os gêneros, incluindo Echium e Heliotropum), Asteraceae, gêneros Senecio e Eupatorium e Leguminoseae gênero Crotalaria (Cheeke 1998).

Os AP contidos nas plantas não são quimicamente reativos, grande parte deles é excretada inalterada. No entanto, podem ser metabolizados no fígado em produtos tóxicos. As principais rotas de metabolismo hepático dos AP são a hidrólise pelo éster, a $\mathrm{N}$-oxidação e a desidrogenação. As duas primeiras reações representam mecanismos de desintoxicação, enquanto que a desidrogenação forma os pirróis e está associada com a toxicidade dos alcalóides. O equilíbrio entre essas reações é que determina o efeito tóxico dos AP (Mattocks 1986). Os pirróis são eletrofílicos e reagem com componentes teciduais nucleofilicos, como ácidos nucléicos e proteínas (Sperl et al. 1995). Como o fígado é local de produção desses pirróis tóxicos, ele é um dos principais órgãos alvo, seguido pelos pulmões (Cheeke 1998). Os pirróis lesam as células hepáticas por inibição da mitose (efeito alquilante), causando megalocitose, necrose e redução no número de hepatócitos, que são substituídos por tecido fibroso; em virtude disso, levam ao aparecimento do quadro clínico e morte decorrente de disfunção hepática (Seawright et al. 1991). Parte dos pirróis produzidos no fígado escapam para a circulação geral, causando lesões em outros tecidos, sendo a causa da nefrose e da pneumonia intersticial que ocorrem algumas intoxicações (Radostits et al. 2002). Outros órgãos, como o pulmão, também produzem pirróis por conterem enzimas do sistema citocromo P450 (Kim et al. 1993).

Diferenças entre as espécies animais no tocante a suscetibilidade a intoxicações pelos AP são relatadas na literatura. A resistência de algumas espécies é o resultado do balanço entre as reações de bioativação, desintoxicação e excreção de alcalóides (Cheeke 1994). Os bovinos e eqüinos são bastante susceptíveis à intoxicação por AP, sendo $30-40$ vezes mais susceptíveis do que os ovinos e caprinos. A diferença parece estar relacionada à capacidade do ovino em detoxificar os AP no fígado, provavelmente relacionada à dieta consumida antes da domesticação. Pequenos ruminantes são menos seletivos quanto a ingestão de alimentos, desenvolvendo, em virtude disso, resistência às toxinas (Ckeeke 1994; Radostits et al. 2002). A resistência dos ovinos é atribuída, também, a uma maior quantidade de microorganismos no rúmen, capazes de biotransformar esses alcalóides com maior eficiência que os bovinos (Craig et al. 1992). As diferentes respostas ou resistência individual dos animais aos AP podem refletir: 1) a detoxificação bacteriana no trato gastrintestinal, 2) a taxa de conversão, no fígado, dos AP a pirróis tóxicos e 3) a capacidade anti-oxidativa individual do animal. A quantidade de AP ingerida na alimentação também é importante (Craig et al. 1991). Alguns autores consideram que as diferenças no metabolismo hepático dos ovinos são mais importantes do que a flora microbiana do rúmen. Diferenças entre raças também são relatadas; experimentos demonstraram que ovinos da raça Merino são relativamente resistentes à intoxicação por E. plantagineum comparados a outras raças (Cheeke 1994).

Em bovinos o quadro clínico caracteriza-se por insufi- 
ciência hepática em conseqüência de lesões crônicas do fígado. Os sinais clínicos são variáveis; geralmente há encefalopatia hepática com apatia ou hiperexcitabilidade, agressividade, pressão da cabeça contra objetos, andar compulsivo ou em círculo e, ocasionalmente, galope descontrolado e violento. Decréscimo nos reflexos dos nervos cranianos, ataxia e fraqueza também podem ser observados. Tenesmo, diarréia e, ocasionalmente, prolapso retal são característicos deste quadro. O curso clínico é, geralmente, de 24-96 horas. Alguns bovinos apresentam emagrecimento progressivo, com diarréia ou não, com um curso clínico que pode ser de até 3 meses, podendo observar-se antes da morte encefalopatia hepática, ou os animais permanecem em decúbito até a morte. Podem observar-se, também, ascite, fotossensibilização, icterícia e edemas de membros e barbela (Tokarnia \& Döbereiner 1984a, Barros et al. 1987, Méndez et al 1987, Karam et al. 2004, Nobre et al. 2004a). Os casos de fotossensibilização apresentam um curso clínico mais prolongado que os casos de encefalopatia hepática, que pode ser de 30-60 dias (Schild et al. 2006).

Na necropsia de bovinos intoxicados o fígado está firme, com superfície irregular e áreas brancas misturadas com áreas vermelho-escura e com aumento no padrão lobular. Há edema do mesentério e parede do abomaso. Icterícia moderada, ascite, hidropericárdio e hidrotórax também podem ser observados. As lesões histológicas do fígado se caracterizam por fibrose, principalmente periportal, megalocitose e proliferação de células dos ductos biliares (Tokarnia \& Döbereiner 1984, Barros et al. 1987, Méndez et al.1987, Karam et al. 2004)

$\mathrm{Na}$ intoxicação pelos AP em ovinos podemos observar três quadros clínicos: intoxicação crônica com fotossensibilização e/ou encefalopatia hepática; intoxicação crônica por cobre secundária; e intoxicação aguda. $\mathrm{Na}$ intoxicação crônica os animais apresentam sinais clínicos variáveis, que incluem emagrecimento progressivo, apatia, fraqueza, perturbações neurológicas como depressão, andar a esmo e desequilibrado, pressão da cabeça contra objetos, icterícia e fotossensibilização. Na necropsia, o fígado apresenta áreas avermelhadas entremeadas por áreas pálidas, firmes ao corte e superfície capsular irregular, espessada e com fibrina. A vesícula biliar está distendida e observa-se ascite, edema de abomaso e do mesentério e shunts portossistêmicos. Histologicamente observa-se fibrose periportal, proliferação de células epiteliais de ductos biliares, hepatomegalocitose e bilestase. No encéfalo observam-se microcavitações, principalmente na substância branca (status spongiosus), características de encefalopatia hepática (Ilha et al. 2001, Dantas et al. 2004).

Achados ultra-estruturais no fígado incluem graus variáveis de degeneração hepatocelular caracterizada pelo acúmulo de numerosas gotas lipídicas no citoplasma das células hepáticas e presença de lisossomos carregados de material eletrodenso que, na maioria dos casos, correspondem à lipofuscina-ceróide. Adicionalmente, há discreta dilatação do retículo endoplasmático rugoso e moderada hiperplasia do retículo endoplasmático liso em algumas regiões do citoplasma dos hepatócitos (Ilha et al. 2001).

A intoxicação por cobre secundária à intoxicação pelos AP em ovinos está associada ao acúmulo excessivo desse metal no fígado em conseqüência da insuficiência hepática provocada pelos AP. O Cu é liberado causando hemólise, hemoglobinúria e icterícia (Ilha et al. 2001).

A intoxicação aguda pela ingestão de $C$. retusa foi descrita em ovinos (Nobre et al. 2005). Os sinais observados incluem anorexia, depressão acentuada, icterícia moderada, incoordenação e decúbito. Os ovinos morrem em 12 horas após os primeiros sinais clínicos. Na necropsia, o fígado apresenta aspecto acentuação do padrão lobular com deposição de fibrina na superfície capsular. A vesícula biliar está distendida e ocorrem hemorragias subepicardicas e subendocárdicas, hidropericárdio, hidrotórax e ascite. Sementes e vagens da planta podem ser encontradas em grandes quantidades no rúmen dos ovinos que morrem da intoxicação. Lesões histológicas no fígado caracterizam-se por necrose centrolobular. As áreas necróticas estão ocasionalmente circundadas por hepatócitos vacuolizados. Essa lesão é semelhante, se não idêntica, ao que é descrito para as fitotoxinas de ação hepatotóxica aguda (Rissi et al. 2007).

Eqüinos intoxicados por AP apresentam icterícia, encefalopatia hepática e fotossensibilização (Gava \& Barros 1997, Nobre et al. 2004a, Pilati \& Barros 2007). Na encefalopatia hepática os animais apresentam apatia ou hiperexcitabilidade, pressão da cabeça contra objetos, andar compulsivo ou em círculo e, ocasionalmente, galope descontrolado e violento. Decréscimo nos reflexos dos nervos cranianos, ataxia e fraqueza também podem ser observados. Outros sinais clínicos incluem anorexia, perda de peso, fotossensibilização e icterícia. Na necropsia o fígado está firme, com superfície irregular e áreas brancas misturadas com áreas vermelho-escuras e com aumento no padrão lobular. Icterícia moderada, ascite, hidropericárdio e hidrotórax também podem ser observados. As lesões histológicas do fígado caracterizam-se por fibrose, principalmente periportal, megalocitose e proliferação de células dos ductos biliares. Áreas multifocais de hemorragias centrolobulares ou mediozonais, por vezes associadas a necrose, são observadas. Os pulmões podem apresentar pneumonia intersticial fibrosante difusa, com espessamento de septos interalveolares, edema e infiltrado inflamatório mononuclear e, principalmente, macrófagos espumosos. No sistema nervoso pode-se observar congestão, discretas hemorragias, principalmente perivasculares e astrócitos Alzheimer tipo II, principalmente no núcleo caudato e no córtex, isolados ou em grupos.

Furanossesquiterpenos (FST). Terpenos e terpenóides são substâncias derivadas do carbono 5 do isopreno (Cheeke 1998). Os sesquiterpenos são tóxicos comuns em plantas. Os subgrupos deles incluem: sesquiterpenos furanóides (furanossesquiterpenos), ipomeanóis, 
ngaiones, lactonas sesquiterpênicas e esporidesmina. Os FST como o ngaione e a miodesmona são óleos essenciais presentes em Lasiospermum bipinnatum e estão contidos também nas folhas e frutos do Myoporum spp. As espécies de Myoporum que causam lesão hepática em ruminantes incluem $M$. laetum, $M$. deserti, $M$. tetrandum e M. tetrandum affin (Radostits et al. 2002). Os óleos essenciais presentes em $M$. deserti foram investigados quimicamente e ao menos 11 diferentes FST foram isolados sendo todos similarmente tóxicos para animais de laboratório. Experimentos com ratos e coelhos que receberam ngaione demonstraram que esse óleo causa um padrão regular de necrose mediozonal nas células do parênquima hepático, apesar de que a necrose centrolobular ou periportal pode ser vista em alguns animais (Seawright et al. 1978). No Brasil, a intoxicação experimental foi reproduzida em ovinos e bovinos (Raposo et al. 1998a,b, 2003, 2004). Nesses casos a necrose hepática não era mediozonal e sim periportal ou centrolobular.

A biotransformação em metabólitos tóxicos é feita pelas oxidases de função mista microssomal (MMFO), as quais ocorrem em maior concentração na zona centrolobular, em concentração intermediária na mediozonal e em menor concentração na região periportal (Kelly 1993). O ngaione e outros óleos FST provenientes do Myoporum requerem metabolismo das MMFO para se transformar em um composto intermediário responsável pela lesão hepática. Quando a atividade do sistema MMFO é baixa, os hepatócitos da região periportal não metabolizam suficientemente o ngaione permanecendo então intactos. Já as outras células com funcionamento normal do MMFO estariam mais suscetíveis aos efeitos danosos provocados pelo ngaione (Seawright et al. 1978).

A hiperplasia acentuada do retículo endoplasmático liso (REL) observada nos animais intoxicados é uma alteração ultra-estrutural que pode ser interpretada como uma resposta do mecanismo de desintoxicação hepática. $O$ REL atua na biotransformação de drogas não-polares, pelo sistema das oxidases de função mista da citocromo P450 (Marzella \& Trump 1991). Tem sido demonstrado que diferentes rebanhos de ovinos podem apresentar diferentes níveis de atividade média de suas MMFO, e que a atividade das enzimas sob condições de campo pode variar com a estação do ano e com a dieta (Seawright et al. 1978).

A intoxicação por FST em ovinos e bovinos causa icterícia, fotossensibilização, estase ruminal, constipação, tenesmo e dor abdominal. Outros sinais incluem depressão, fezes ressequidas com muco e sangue, mucosas vermelhas, tenesmo, ranger de dentes e dispnéia. $\mathrm{Na}$ necropsia há icterícia e o fígado está aumentado de volume, amarelo ou levemente alaranjado. A vesícula biliar está distendida e com parede edemaciada. Podem-se observar ainda hemorragias petequiais difusas no tecido subcutâneo e nas serosas; presença de líquido seroso nas cavidades; hemorragias no pericárdio, no endocárdio, na mucosa dos intestinos delgado e grosso, e fezes duras recobertas por sangue coagulado no reto. $\mathrm{Na}$ histologia observa-se necrose zonal, que pode ser periportal ou centrolobular (Allen et al. 1978, Raposo et al. 1998ab, 2003, 2004). Essas variações são atribuídas a variações individuais ou à concentração do princípio tóxico da planta e a atividade das MMFO. O uso de prétratamentos com fenobarbital e óleo de Melaleuca linariifolia, que acentuam a atividade das MMFO hepáticas leva a necrose periportal. A zona de localização da lesão na intoxicação por Myoporum é relacionada à prévia utilização das MMFO hepáticas induzidas por compostos alimentares (Allen et al. 1978, Raposo et al. 2003). Outros autores observaram em casos espontâneos necrose hemorrágica mediozonal (Odriozola et al. 1987) e periportal (Jerrett \& Chinnock 1983), e necrose periportal em estudos experimentais (Ford \& Rivera 1978, Jerrett \& Chinnock 1983). A ocorrência de intoxicação por Myoporum spp. ou outras por substâncias hepatotóxicas está na dependência de sua metabolização, pelo fígado, a metabólitos intermediários hepatotóxicos. Bovinos demonstraram menor sensibilidade aos efeitos de Myoporum laetum (Raposo et al. 2003), o que provavelmente está associado a uma menor atividade das enzimas microssomais hepáticas nessa espécie. Além dos diferentes padrões de necrose hepática mencionados anteriormente, outros achados histológicos observados na intoxicação de ovinos por Myoporum laetum incluem vacuolização de hepatócitos, fibrose portal e proliferação de ductos biliares. Estudos ultra-estruturais revelam hiperplasia do retículo endoplasmático liso, tumefação de hepatócitos, desgranulação e vesiculação do retículo endoplasmático rugoso, presença de cristais aciculares, retenção biliar, tumefação de mitocôndrias e várias outras alterações degenerativas. Em bovinos, tanto os achados histológicos, quanto os ultra-estruturais são menos evidentes do que em ovinos (Raposo et al. 1998b, 2003, 2004). Há correlação entre sinais clínicos, lesões hepáticas e a elevação dos níveis séricos de AST, GGT e BLT na intoxicação de ovinos por M. laetum (Raposo et al. 2004).

Triterpenos. Os ácidos triterpênicos (Lantadene A e B) estão presentes em Lantana spp. No Brasil a intoxicação por L. camara, L. tiliaefolia e L. glutinosa têm sido diagnosticada (Riet-Correa et al. 1984, Tokarnia et al. 1984, Brito e Tokarnia 1995, Tokarnia et al. 1984b, 1999, Brito et al. 2004). As toxinas da Lantana são absorvidas rapidamente pelo trato alimentar após da ingestão da planta; chegam até o fígado pela circulação portal e dentro de poucos minutos provocam o quadro de colestase intrahepática (Pass et al. 1978).

Os triterpenos são metabolizados pelas enzimas do sistema microssomal hepático se transformando em metabólitos ativos. Essas toxinas causam colestase intrahepática (retenção de bile no fígado) pela inibição da secreção da bile pelos hepatócitos. Os metabólitos do lantadene provocam lesão na membrana das células dos canalículos biliares. As principais conseqüências da co- 
lestase são fotossensibilização, icterícia e estase ruminal. Fotossensibilização ocorre devido ao impedimento da excreção biliar de bilirrubina. Estase ruminal que é proeminente na intoxicação pela Lantana ocorre aparentemente pela diminuição do reflexo hepato-ruminal, processo que é iniciado pela injúria do tecido hepático (Cheeke 1998). Os FST provocam também nefrose tubular (RietCorrea et al.1984, Tokarnia et al. 1984).

A intoxicação por Lantana spp. está associada à perda de ATPases canaliculares que são distribuídas na membrana canalicular dos ovinos. Foi demonstrado que dentro de 6 horas após administração oral da planta, há uma perda de ATPases na região centrolobular ou periacinar. Após 24 horas há uma perda total de ATPases no lóbulo hepático. Seis horas após a ingestão da planta as microvilosidades das células canaliculares estão fragmentados, e 24 horas depois, o colapso canalicular é completo. Em alguns casos, entretanto, a região periportal é poupada (Pass et al. 1978).

Embora a secreção biliar esteja reduzida na intoxicação por Lantana spp, aparentemente os hepatócitos conservam seu metabolismo funcional. Isso é evidenciado pelo fato de que $60 \%$ da bilirrubina retida é conjugada (Pass et al 1978). O nível de bilirrubina sérica nos animais intoxicados é muito maior do que nos animais sadios. Nos animais sadios $30 \%$ da bilirrubina circulante está na forma conjugada. A conjugação da bilirrubina ocorre pela atividade do sistema oxidase de função mista no retículo endoplasmático agranular dos hepatócitos. Foi demonstrado um aumento da área do retículo endoplasmático agranular nos hepatócitos de animais intoxicados demonstrando que estes também são afetados na intoxicação pelos triterpenos. A distensão da vesícula biliar é outro achado importante da intoxicação pela Lantana. É atribuída a paralisia do músculo liso da vesícula biliar (Pass et al 1978).

Lantana spp. são plantas com sabor desagradável e os bovinos só as ingerem se outros alimentos são escassos ou em caso de animais transportados. A susceptibilidade de ovinos é semelhante à dos bovinos (Brito et al 2004), mas os bovinos taurinos são mais suscetíveis do que os zebuínos (Radostits et al. 2002).

O quadro clínico-patológico observado na intoxicação por Lantana spp. é caracterizado por: acentuada icterícia, globos oculares retraídos, marcado emagrecimento, urina de coloração amarelada, constipação, fezes ressequidas, pêlos arrepiados, fraqueza e fotossensibilzação nas partes despigmentadas da superfície do corpo, caracterizadas inicialmente por vermelhidão (congestão), edema, aparecimento de exsudato na superfície das áreas afetadas, seguidas por formação de fendas e de mumificação da pele nas partes afetadas. Os animais podem apresentar sinais nervosos incluindo andar lerdo, apatia, decúbito esternal com a cabeça encostada no flanco, desorientação, estado semelhante à embriaguez, andar em círculos e agressividade (Riet-Correa et al. 1984, Tokarnia et al. 1984, 1999, Brito \& Tokarnia 1995, Brito et al. 2004). É importante ressaltar que exis- te uma variação na toxicidade das diferentes espécies de Lantana e dentro da mesma espécie oriundas de regiões distintas (Brito et al. 2004).

Na necropsia observa-se icterícia generalizada e edema subcutâneo amarelo-intenso, localizado principalmente nos membros. O fígado apresenta-se aumentado de tamanho, de coloração alaranjada ou amarela. A vesícula biliar está distendida e edemaciada. Pode-se observar ainda hemorragias petequiais difusas no tecido subcutâneo e nas serosas, presença de líquido seroso nas cavidades, hemorragias no pericárdio, no endocárdio, na mucosa dos intestinos delgado e grosso, e fezes duras recobertas por sangue coagulado no reto. As lesões microscópicas revelam, além de bilestase, alterações degenerativas nos hepatócitos periportais e nas células epiteliais dos túbulos uriníferos (Riet-Correa et al. 1984, Tokarnia et al. 1984, 1999, Brito \& Tokarnia 1995, Brito et al. 2004).

Saponinas esteroidais. Saponinas esteroidais são glicosídeos com núcleo tipo furostanólico ou espirostanólico, que contém uma ou várias cadeias de açúcares. Seu nome deriva da propriedade mais característica desse grupo de compostos, que é a formação de espuma persistente e abundante quando em solução aquosa (Santos 2000). As espécies de Brachiaria e outras plantas (Panicum spp., Tribulus terrestris, Agave lechiguilla e Nathercium ossifragum) contêm saponinas esteroidais que estão associadas com a deposição de material cristalóide no sistema biliar, colangite e fotossensibilização (Miles et al. 1991, Cruz et al. 2001).

A hidrólise das saponinas de Brachiaria decumbens (protodioscina) e outras plantas (dicotomina em Panicum spp.) resulta nas sapogeninas diosgenina e iamogenina (Meagher et al. 1996), que após serem metabolizadas no trato digestivo dos animais vão resultar na sapogeninas epismilagenina e episarsasapogenina, respectivamente, que são responsáveis pela formação dos cristais biliares. Mecanismo provável para a formação dos cristais biliares envolve a hidrólise dos açúcares da saponinas pelo metabolismo ruminal, seguida pela redução da dupla ligação (C5-C6), epimerização do radical $3-\beta-\mathrm{OH}$ para $3-\alpha-\mathrm{OH}$ e, finalmente, conjugação com o ácido glicurônico. Os glicuronídeos de epismilagenina e episarsasapogenina ligam-se com os íons de cálcio e formam sais insolúveis que se depositam na forma de cristais (Miles et al. 1991). Os cristais causam inflamação e obstrução do sistema biliar, além de necrose dos hepatócitos periportais resultando em icterícia, fotossensibilização e hepatite. Encontram-se, também, cristais aciculares nos hepatócitos, células de Kupffer e células dos túbulos renais (Radostits et al. 2002). O material cristalóide pode causar fotossensibilização e icterícia pelo bloqueio físico ao fluxo da bile, ou os metabólitos das saponinas podem causar uma colestase especifica com ação similar ao Lantadene A (Cruz et al. 2000).

Os ovinos são mais sensíveis do que os bovinos à intoxicação e os animais jovens são mais sensíveis que os adultos. No Brasil são descritos casos clínicos em bo- 
vinos, ovinos, caprinos e bubalinos (Lemos et al. 1996a, 1997, 1998a, Tokarnia et al. 2000, Seitz et al. 2004, Rozza et al. 2004). Também são descritos casos de fotossensibilização hepatógena em equinos pela ingestão de $B$. humidicola (Barbosa et al. 2006).

Quando os animais são expostos ao sol apresentam inquietação, balançam a cabeça e as orelhas, esfregam ou coçam as áreas afetadas em objetos e procuram a sombra. As lesões de pele iniciam com eritema, seguido de edema, fotofobia e dor. Ocorre espessamento das partes afetadas da pele, com presença de exsudato e formação de crostas. O resultado é uma necrose e gangrena seca deixando a pele lesada com aspecto de casca de árvore que, finalmente, se desprende. São observados diferentes graus de icterícia, bilirrubinemia e bilirrubinúria (Tokarnia et al. 2000, Lemos et al. 2002). As lesões são mais graves nas regiões dorsais do corpo e nas partes expostas ao sol quando os animais se deitam (Radostits et al. 2002). As orelhas apresentam-se contorcidas e com os bordos voltados para cima, podendo haver ulcerações na parte ventral da língua, ceratite, opacidade de córnea e cegueira (Lemos et al. 2002). Há um aumento significativo nos níveis de GGT e AST (Lemos et al. 1996b, 2002).

Na necropsia, além das lesões de pele, de língua e oculares descritas anteriormente, podem observam-se diversos graus de icterícia. O fígado está aumentado de volume com coloração amarelo-cobre intensa. Há aumento de consistência e extensas áreas de fibrose em casos mais crônicos. A vesícula biliar pode se apresentar distendida e com bile viscosa e espessa. Os rins podem estar escurecidos e a urina também pode ter coloração castanho-escura (Lemos et al. 2002). Em casos crônicos, o fígado apresenta coloração amarelada, que se evidencia ainda mais após um período de 24 horas de fixação em formol a $10 \%$ (Driemeier et al. 1998, Riet-Correa et al. 2002). Nestes casos os linfonodos hepáticos e mesentéricos não apresentam alterações de tamanho ou alterações externas, mas na superfície de corte podem ser observadas inúmeras estriações paralelas de cor branca semelhantes a giz, dispostas em forma radiada paralela da cortical em direção à medular. Alguns linfonodos podem apresentar, na região medular, pequenos nódulos brancos semelhantes aos da região cortical, e que se projetam levemente na superfície de corte. Alguns animais podem apresentar, além disso, áreas vermelhas escuras irregulares distribuídas principalmente na cortical, por vezes intercaladas com finas estriações esbranquiçadas (Driemeier et al. 1998).

Histologicamente observam-se cristais nos ductos biliares e macrófagos espumosos, às vezes com cristais no citoplasma. Pode haver necrose e degeneração de hepatócitos periportais, proliferação de células dos ductos biliares, estase biliar, colangite, pericolangite e fibrose periportal. Podem observar-se macrófagos espumosos nos linfonodos, baço. (Lemos et al., 1996a,b,c, 1997, 1998, 2002, Driemeier et al.1998) e, ocasionalmente, no intestino (Riet-Correa et al. 2002).

O estudo ultra-estrutural do fígado demonstra a pre- sença de estruturas em forma de fendas com imagem negativa de cristais, presentes nos macrófagos e hepatócitos. Nesses últimos, pode-se observar acentuada hiperplasia do retículo endoplasmático liso. Muitas destas estruturas são delimitadas parcial ou totalmente por membrana. Nos linfonodos hepáticos e mesentéricos podem-se observar macrófagos contendo estruturas cristalóides semelhantes às contidas nos hepatócitos. Macrófagos degenerados e/ou em necrose também são visualizados (Driemeier et al. 1998).

\section{REFERÊNCIAS}

Allen J.G., Seawrigth A.A. \& Hrdlicka J. 1978. The toxicity of Myporum tetradum (Boobialla) and myoporaceous furanoid essential oils for ruminants. Aust. Vet. J. 54:287-292.

Barbosa J.D., Oliveira C.M.C., Tokarnia C.H. \& Peixoto P.V. 2006. Fotossensibilização hepatógena em eqüinos pela ingestão de Brachiaria humidicola (Gramineae) no Estado do Pará. Pesq. Vet. Bras. 26:147153.

Barros C.S.L., Castilhos L.M.L., Rissi D.R., Kommers G.D. \& Rech R.R. 2007. Biópsia hepática no diagnóstico da intoxicação por Senecio brasiliensis em bovinos Pesq. Vet. Bras. 27:53-60.

Barros C.S.L., Metdzorf L.L. \& Peixoto P.V. 1987. Ocorrência de surtos de intoxicação por Senecio spp. (Compositae) em bovinos no Rio Grande do Sul. Pesq. Vet. Bras. 7:101-107.

Barros C.S.L., Driemeier D., Pilati C., Barros S.S. \& Castilhos L.M.L. 1992. Senecio spp. poisoning in cattle in southern Brazil. Vet. Human Toxicol. 34:241-246.

Brito M.F. \& Tokarnia C.H. 1995. Estudo comparativo da toxidez de Lantana camara var. aculeata em bovinos e ovinos. Pesq. Vet. Bras. 15:79-84.

Brito M.F., Tokarnia C.H. \& Döbereiner J. 2004. A toxidez das diversas lantanas para bovinos e ovinos no Brasil. Pesq. Vet. Bras. 24(3):153159.

Brum K.B., Purisco E., Lemos R.A.A. \& Riet-Correa F. 2002. Intoxicação por Vernonia rubricaulis em bovinos no Mato Grosso do Sul. Pesq. Vet. Bras. 22:119-128.

Canella C.F.C., Tokarnia C.H. \& Döbereiner J. 1968. Intoxicação por Sessea brasiliensis Toledo em bovinos. Pesq. Vet. Bras. 3:333-340.

Cattani C.S.O., Colodel E.M., Traverso S.D., Correa A.M.R. \& Driemeier D. 2004. Intoxicação experimental por Dodonea viscosa em bovinos. Pesq. Vet. Bras. 24:31-34.

Cheeke P.R. 1994. A review of the functional and evolutionary roles of the liver in the detoxification of poisonous plants, with special reference to pirrolizidine alkaloids. Vet. Human Toxicol. 36:240-247.

Cheeke P.R. 1998. Natural Toxicants in Feeds, Forages, and Poisonous Plants. $2^{\text {nd }}$ ed. Interstate, Danville, Illinois. 479p.

Coles E.H. 1984. Patologia Clínica Veterinária. $3^{\underline{a}}$ ed. Manole, São Paulo, p.185-219.

Colodel E.M., Driemeier D. \& Pilati C. 2000. Intoxicação experimental pelos frutos de Xanthium cavanillesii (Asteraceae) em bovinos. Pesq. Vet. Bras. 20:31-38.

Colodel E.M., Traverso S.D, Seitz A.L., Oliveira F.N., Driemeier D. \& Gava A. 2003. Spontaneous poisoning by Dodonea viscosa (Sapindaceae) in cattle. Vet. Human Toxicol. 45:47-148.

Craig A.M., Pearson E.G., Meyer C. \& Schmitz A. 1991. Clinicopathologic studies of tansy ragwort toxicosis in ponies: sequential serum and histophatological changes. Eq. Vet. Sci. 11: 261-281.

Craig A.M., Latham C.J., Blythe L.L., Schmotzer W.B. \& O'Connor O.A. 1992. Metabolism of toxic pyrrolizidine alkaloids from tansy ragwort (Senecio jacobaea) in ovine ruminal fluid under anaerobic conditions. Appl. Environ. Microbiol. 58:2730-2736. 
Cruz C., Driemeier D. \& Pires V.S. 2000. Isolation of steroidal sapogenins implicated in experimentally induced cholangiopathy of sheep grazing Brachiaria decumbens in Brazil. Vet. Human Toxicol. 42:142-145.

Cruz C., Driemeier D., Pires V.S. \& Schenkel E.P. 2001. Experimentally induced by dosing sheep with fractionated extracts from Brachiaria decumbens. J. Vet. Diagn. Invest. 73:170-172.

Cullen J.M. 2007. Liver, biliary system and exocrine pancreas, p.393461. In: McGavin M.D. \& Zachary J.F. (ed.), Pathologic Basis of Veterinary Disease. $4^{\text {th }}$ ed. Mosby Elsevier, St Louis.

Curran J.M., Sutherland R.J. \& Peet R.L. 1996. A screening test for subclinical liver disease in horses affected by pyrrolizidine alkaloid toxicosis. Aust. Vet. J. 74:236-240.

Dantas A.F.M., Nobre V.M.T., Riet-Correa F., Tabosa I.M., Júnior G.S., Medeiros J.M., Silva R.M.N., Silva E.M.N. \& Anjos B.L. 2004. Intoxicação crônica espontânea por Crotalaria retusa (Febaceae) em ovinos na região do semi-árido paraibano, Brasil. Pesq. Vet. Bras. 24(Supl.):18-19.

Deutsch J., Döbereiner J.V. \& Tokarnia C.H. 1965. Fotossensibilidade hepatogênica em bovinos na intoxicação pela fava de Enterolobium gummiferum. 9o Congr.Int. Pastagens, São Paulo, p.1279-1282.

Döbereiner J., Tokarnia C.H. \& Canella C.F. 1969. Intoxicação por Cestrum laevigatum Schlecht., a causa de mortantades em bovinos no Estado do Rio de Janeiro. Pesq. Agropec. Bras. 4:165-193.

Döbereiner J., Tokarnia C.H. \& Purisco E. 1976. Vernonia mollissima, planta tóxica responsável por mortandade de bovinos no Sul do Mato Grosso. Pesq. Agropec. Bras. 11:49-58.

Driemeier D., Barros S.S., Peixoto P.V., Tokarnia C.H., Döbereiner J. \& Brito M.F. 1998. Estudos histológicos, histoquímicos e ultra-estruturais de fígado e linfonodos de bovinos com presença de macrófagos espumosos ("foam cells"). Pesq. Vet. Bras. 18(1):29-34.

Driemeier D., Irigoyen L.F., Loretti A.P., Colodel E.M. \& Barros C. S. L. 1999. Intoxicação espontânea pelos frutos de Xanthium cavanillesii (Asteraceae) em bovinos no Rio Grande do Sul. Pesq. Vet. Bras. 19(1):12-18.

Ford E.J.H. \& Rivera R. 1978. The modification of the dehydromyodesmone-induced hepatic lesion in cattle by microssomal drug metabolizing enzymes. J. Comp. Path. 88:365-380.

Gava A. \& Barros C.S.L. 1997. Senecio spp. poisoning in horses in southern Brazil. Pesq. Vet. Bras. 17:36-40.

Gava A., Stolf L., Pilati C., Neves D.S. \& Vigano L. 1991. Intoxicação por Cestrum corymbosum var. hirsutum (Solanaceae) em bovinos no Estado de Santa Catarina. Pesq. Vet. Bras. 11:71-74.

Gava A., Stolf L. \& Varaschin M.S. 1996. Intoxicação por Cestrum intermedium (Solanaceae) em bovinos. Pesq. Vet. Bras. 16:7-20.

Grecco F.B., Dantas F.A.M., Riet-Correa F., Leite C.G.D. \& Raposo J. 2002. Cattle intoxication from Enterolobium contortisiliquum pods. Vet. Human Toxicol. 44:160-162.

Hooper P.T. 1975. Spongy degeneration in the central nervous system of domestic animals. Part III. Occurrence and pathogenesis of hepatocerebral disease caused by hyperammonaemia. Acta Neuropathologica 31:343-351.

Hooper P.T., Best S.M. \& Murray D.R. 1974. Hyperammonaemia and spongy degeneration of the brain in sheep affected with hepatic necrosis. Res. Vet. Sci. 16:216-222.

Ilha M.R.S., Loretti A.P., Barros S.S. \& Barros C.S.L. 2001. Intoxicação espontânea por Senecio brasiliensis (Asteraceae) em ovinos no Rio Grande do Sul. Pesq. Vet. Bras. 21(3):123-138.

Jerret I.V. \& Chinnock R.J. 1983. Outbreaks of the photosensitization and deaths in cattle due to Myoporum aff. insulare. Aust.Vet. J. 60:183-186.

Kaneko J.J. 1989. Clinical Biochemistry of Domestic Animals. $4^{\text {th }}$ ed. Academic Press, San Diego, p.877-901.

Karam F.S.C., Soares M.P., Haraguchi M., Riet-Correa F., Mendez M.C. \& Jarenkow J.A. 2004. Aspectos epidemiológicos da seneciose na região sul do Rio Grande do Sul. Pesq. Vet. Bras. 24:191-198.
Kellerman T.S., Coetzer J.A.W., Naudé C.J. \& Botha C.J. 2005. Plant Poisonings and Mycotoxicoses of Livestock in Southern Africa. $2^{\text {nd }}$ ed. Oxford University Press, Cape Town. 310 p.

Kelly W.R. 1993. The liver and biliary system, p.319-404. In: Jubb K.V.F., Kennedy P.C. \& Palmer N. (ed.), Pathology of Domestic Animals. Vol.2. $4^{\text {th }}$ ed. Academic Press, San Diego.

Kelly W.R. 2002. Enfermedad del hígado en grandes y pequeños rumiantes. $10^{\circ}$ Congr. Latinoamericano de Buiatria, $30^{\mathrm{a}}$ Jornadas Uruguayas de Buiatria. Paysandú, Uruguai, p.1-6.

Kerr M.G. 2003. Exames Laboratoriais em Medicina Veterinária, Bioquímica Clínica e Hematologia. $2^{\underline{a}}$ ed. Roca, São Paulo, p.154-155.

Kim H.Y., Stermitz F.R., Wilson D.W., Taylor D. \& Coulombe Jr R.A. 1993. Characterization of pyrrolizidine alkaloids-induced DNA-protein cross-link. Carcinogenesis 16:2691-2697.

Kramer J.W. \& Hoffmann W.E. 1997. Clinical enzymology, p.303-325. In: Kaneko J.J. (ed.), Clinical Biochemistry of Domestic Animals. 5th ed. Academic Press, San Diego.

Lemos R.A.A., Ferreira L.C.L., Silva S.M., Nakazato L. \& Salvador S.C. 1996a. Fotossensibilização e colangiopatia associada a cristais em ovinos em pastagem de Brachiaria decumbens. Ciência Rural 26:109113.

Lemos R.A.A., Oliveira V.A., Herrero Júnior G.O., Silveira A.C. \& Porfírio L.C. 1996b. Fotossensibilização e colangiopatia associada a cristais em bovinos lactentes associada a ingestão de Brachiaria decumbens. $15^{\circ}$ Congr. Panam. Med. Vet., Campo Grande, MS, p.170. (Resumo)

Lemos R.A.A., Osório A.L.A.R., Rangel J.M.R. \& Herrero Júnior G.O. 1996c. Fotossensibilização e colangiopatia associada a cristais em bezerros ingerindo Brachiaria brizantha. Arqs Inst. Biológico, São Paulo, 63(Supl.):22.

Lemos R.A.A., Salvador S.C. \& Nakazato L. 1997. Photosensitization and crystal associated cholangiohepatopathy in catlle grazin Brachiaria decumbens in Brazil. Vet. Human Toxicol. 39:376-377.

Lemos R.A.A., Nakazato L. \& Del Pozo C.F. 1998a. Intoxicação por Brachiaria sp., p.299-306. In: Lemos RA.A. (ed.), Principais Enfermidades de Bovinos de Corte do Mato Grosso do Sul. Universidade Federal do Mato Grosso do Sul, Campo Grande.

Lemos R.A., Purisco L., Nakazato L., Bonilha R., Gattass C.B.A. \& Brum K.B. 1998b. Intoxicação experimental por Enterolobium timbouva Mart. em bovinos. Arqs Inst. Biológico, São Paulo, 65(Supl.):109.

Lemos R.A.A. \& Purisco E. 2002. Plantas que causam fotossensibilização hepatógena, p.297-315. In: Lemos R.A.A., Barros N. \& Brum K.R. (ed.), Enfermidades de Interesse Econômico em Bovinos de Corte: perguntas e respostas. Universidade Federal de Mato Grosso do Sul, Campo Grande. 292p.

Loretti A.P., Bezerra P.S., Ilha M.R.S., Barros S.S. \& Barros C.S.L. 1999. Intoxicação experimental pelos frutos de Xanthium cavanillesii (Asteraceae) em ovinos. Pesq. Vet. Bras. 19:68-75.

Luciani S., Carpenedo F. \& Tarjan E.M. 1978. Effects of atractyloside and carboxyatractyloside in the whole animal, p.109-124. In: Santi R. \& Luciani S. (ed.), Atractyloside. Piccin Medical Books, Padova.

Marzella L. \& Trump B.J. 1991. Pathology of the liver: Functional and structural alterations of the hepatocyte organelles induced by cell injury, p.93-138. In: Meeks R.G., Harrison S.D. \& Bull R.J. (ed.), Hepatotoxicology. CRC Press, Boca Raton.

Mattocks A.R. 1986. Chemistry and Toxicology of Pyrrolizidine Alkaloids. Academic Press, London. 393p.

Meagher L.P., Miles C.O. \& Fagliari J.J. 1996. Hepatogenous photosensibilization of ruminants by Brachiaria decumbens and Panicum dichotomiflorum in the absence of sporidesmin: lithogenic saponins may be responsible. Vet. Human Toxicol. 38(4):271-274.

Méndez M.C., Riet-Correa F., Schild A.L. \& Garcia J.T.C. 1985. Intoxicação por Echium plantagineum (Boraginaceae) em bovinos no Rio Grande do Sul. Pesq. Vet. Bras. 5:57-64. 
Méndez M.C., Riet-Correa F. \& Schild A.L. 1987. Intoxicação por Senecio em spp. em bovinos no Rio Grande do Sul. Pesq. Vet. Bras. 7:51-56.

Méndez M.C. \& Riet-Correa F. 1993. Intoxication by Senecio tweediei in cattle in southern Brazil. Vet. Human Toxicol. 35:55.

Meyer D.J., Coles E.H. \& Rich L.J. 1995. Medicina de Laboratório Veterinária: interpretação e diagnóstico. 1aㅡ ed. Roca, São Paulo. 320p.

Miles C.O., Munday S.C., Holland P.T., Smith B.L., Embling P.P. \& Wilkins A.L. 1991. Identification of a sapogenin glucoronide in the bile of sheep affected by Panicum dichotomiflorum toxicosis. N. Z. Vet. J. 39:150-152.

Morais M.G., Rangel J.M., Madureira J.S. \& Silveira A.C. 2000. Variação sazonal da bioquímica clinica de vacas aneroladas sob pastejo contínuo de Brachiaria decumbens. Arq. Bras. Med. Vet. Zootec. 52:98104.

Nobre D., Dagli M.L.Z. \& Haraguchi M. 1994. Crotalaria juncea intoxication in horses. Vet. Human Toxicol. 36:445-448.

Nobre V.M.T., Riet-Correa F., Barbosa Filho J.M., Dantas A.F.M., Tabosa I.M. \& Vasconcelos J.S. 2004a. Intoxicação por Crotalaria retusa L. (Fabaceae) em eqüídeos no semi-árido da Paraíba. Pesq. Vet. Bras. 24(3):132-143.

Nobre V.M.T., Riet-Correa F., Dantas A.F.M., Tabosa I.M., Medeiros R.M.T. \& Barbosa Filho J.M. 2004b. Intoxication by Crotalaria retusa in ruminants and eqüidae in the state of Paraíba, northeastern Brazil, p.275-278. In: Acamovich T., Stewart C.S. \& Pennycott T.W. (ed.), Plant Poisoning and Related Toxins. CAB International, Glasgow, UK.

Nobre V.M.T., Dantas A.F.M., Riet-Correa F., Barbosa Filho J.M., Tabosa I.M. \& Vasconcelos J.S. 2005. Acute intoxication by Crotalaria retusa in sheep. Toxicon 45:347-352.

Odriozola E.R., Tapia M.O., Lopez T.A., Casaro A.P. \& Calandra W. 1987. Intoxicación natural de bovinos com transparente (Myoporum laetum Forst.). Revta Med. Vet., Buenos Aires, 68:230-232.

Pass M.A., Pollitt S., Goosem M.W. \& Mcsweeney C.S. 1978. The pathogenesis of Lantana poisoning, p.487-493. In: Keller R.F., Van Kampen K. \& James L.F. (ed.), Poisonous Plants: effects on livestock. Academic Press, New York.

Peixoto P.V., Brust L.C., Duarte M.D., França T.N. \& Duarte V.C. 2000. Cestrum laevigatum poisoning in goats in southeastern Brazil. Vet. Human Toxicol. 42:13-14.

Pilati C. \& Barros C.S.L. 2007. Intoxicação experimental por Senecio brasiliensis (Asteraceae) em eqüinos Pesq. Vet. Bras. 27(7):251-260.

Radostits O.M., Gay C.C., Blood D.C. \& Hinchcliff K.W. 2002. Clínica Veterinária: um tratado de doenças dos bovinos, ovinos, suínos, caprinos e eqüinos. 9 ${ }^{a}$ ed. Guanabara Koogan, Rio de Janeiro, p.347-360.

Raposo J.B., Méndez M.C., Andrade G.B. \& Riet-Correa F. 1998a. Experimental intoxication by Myoporum laetum in sheep. Vet. Human Toxicol. 40:132-135

Raposo J.B., Méndez M.C., Andrade G.B. \& Riet-Correa F. 1998b. Experimental intoxication by Myoporum laetum in cattle. Vet. Human Toxicol. 40:273-275.

Raposo J.B., Driemeier D., Barros S.S. \& Gevehr-Fernandes C. 2003. Evolução das lesões histológicas e ultra-estruturais de ovinos e bovinos intoxicados experimentalmente por Myoporum laetum. Pesq. Vet. Bras. 23:149-155.

Raposo J.B., Gevehr-Fernandes C., Baialardi C. \& Driemeier D. 2004. Observações clínicas e bioquímicas de ovinos e bovinos intoxicados experimentalmente por Myoporum laetum. Acta Sci. Vet. 32:9-17.

Riet-Correa F., Schild A.L. \& Méndez M.C. 1986. Intoxicação por Cestrum parqui (Solanaceae) em bovinos no Rio Grande do Sul. Pesq. Vet. Bras. 6:111-115.

Riet-Correa F., Méndez M.C., Schild A.L., Riet-Correa I. \& Silva Neto S.R. 1984. Intoxicação por Lantana glutinosa em bovinos no Estado de Santa Catarina. Pesq. Vet. Bras. 4:147-153.
Riet-Correa G., Riet-Correa F., Schild A.L. \& Driemeier D. 2002. Wasting and death in cattle associated with chronic grazing of Brachiaria decumbens. Vet. Human Toxicol. 44:179-180.

Rissi D.R., Driemeier D., Silva M.C., Barros R.R. \& Barros C.S.L. 2007. Poisonous plants producing acute hepatic disease in Brazilian cattle, p.72-76. In: Panter K.E., Wierenga T.L. \& Pfister J.A. (ed.), Poisonous Plants: global research and solutions. CAB International, Wallingford, Oxfordshire.

Rozza D.B., Seitz A.L., Bandarra P.M., Santos E.O. \& Driemeier D. 2004. Fotossensibilização por Brachiaria decumbens em búfalo. Pesq. Vet. Bras. 24(Supl.):55-56.

Santos R.C., Méndez M.C., Riet-Correa F. 1998. Intoxication by Xanthium cavanillesii in cattle and sheep in southern Brazil. Vet. Human Toxicol. 40:144-147.

Santos R.I. 2000. Metabolismo básico e origem dos metabólitos secundários, p.323-354. In: Simões C.M.O., Schenkel E.P., Gosmann G., Mello J.C.P., Mentz, L.A. \& Petrovick, P.R. (ed.), Farmacognosia da Planta ao Medicamento. Editora da UFRGS/Editora da UFSC, Porto Alegre.

Santos J.C.A., Riet-Correa F., Dantas A.F., Barros S.S., Molyneux R.J., Medeiros R.M.T., Silva D.M., Oliveira O.F. 2007. Toxic hepatopathy in sheep associated with the ingestion of the legume Tephrosia cinerea. J. Vet. Diag. Invest. 19:690-694.

Scheffer J.F.S. \& González F.H. D. 2006. Enzimologia Clínica em Medicina Veterinária. Disponível em http://www6.ufrgs.br/bioquimica/ index.htm. Acesso em 4.9.06.

Schild A.L., Mota A.C., Riet-Correa F., Karan F.C. \& Grecco F.B. 2006. Photosensitization in cattle in southern Brazil, p.162-166. In: Acamovicc T., Stewart C.S. \& Pennycott T.W. (ed.), Poisonous Plants and Related Toxins, CAB Publishing, Wallingford.

Seawright A.A., Lee J.S., Allen J.G. \& Hrdlicka J. 1978. Toxicity of Myoporum spp. and their furanosequiterpenoid essential oils, p.241250. In: Keeler R.F., Van Kampen K.R. \& James L.F. (ed.), Effects of Poisonous Plants on Livestock. Academic Press, New York.

Seawright A.A., Kelly W.R., Hrdlicka J., McMahon P., Mattocks A.R. \& Jukes R. 1991. Pyrrolizidine Alkaloids in cattle due to Senecio species in Australia. Vet. Rec. 31:188-189.

Seitz A.L., Rozza D.B., Feltrin C., Traverso S.D., Colodel E.M. \& Driemeier D. 2004. Fotossensibilização por Brachiaria decumbens em ovinos no Rio Grande do Sul. Pesq. Vet. Bras. 24(Supl.): 67.

Smith B.P. 2002. Large Animal Internal Medicine. $3^{\text {rd }}$ ed. Mosby, St Louis. 1735p.

Souza R.M., Birgel Júnior E.H., Ayres M.C.C. \& Birgel E.H. 2004. Influência dos fatores raciais na função hepática de bovinos da raça Holandesa e Jersey. Braz. J. Vet. Res. An. Sci. 41:306-312.

Sperl W., Stuppner H., Gassner I., Judmaier W., Dietze O. \& Vogel W. 1995. Reversible hepatic veno-oclusive disease in na infant after consumption of pirrolizidine-containing herbal tea. Eur. J. Pediatr. 154:112-116

Tennant B.C. 1997. Hepatic function, p.327-352. In: Kaneko J.J., Harvey, J.W.\& Bruss M. (ed.), Clinical Biochemistry of Domestic Animals. $5^{\text {th }}$ ed. Academic Press, San Diego.

Tokarnia C.H., Canella C.F.C. \& Döbereiner J. 1960. Intoxicação experimental pela fava da "timbaúba" Enterolobium contortisiliquum (Vell.) Morong em bovinos. Arqs Inst. de Biológico, São Paulo, 3:73-81.

Tokarnia C.H. \& Döbereiner J. 1982. Intoxicação de bovinos por Vernonia rubricaulis (Compositae) em Mato Grosso. Pesq. Vet. Bras. 2:143:147.

Tokarnia C.H. \& Döbereiner J. 1984. Intoxicação experimental por Senecio brasiliensis (Compositae) em bovinos. Pesq. Vet. Bras. 4:3965.

Tokarnia C.H., Döbereiner J., Lazzari A.A. \& Peixoto P.V. 1984. Intoxicação por Lantana spp. (Verbenaceae) em bovinos nos Estados de Mato Grosso e Rio de Janeiro. Pesq. Vet. Bras. 4:129-141. 
Tokarnia C.H., Peixoto P.V., Gava A. \& Döbereiner J. 1991. Intoxicação experimental por Stryphnodendron coriaceum (Leg. Mimosoideae) em bovinos. Pesq. Vet. Bras. 11:25-29.

Tokarnia C.H., Armién A.G., Barros S.S., Peixoto P.V. \& Döbereiner J. 1999. Estudos complementares sobre a toxidez de Lantana camara (Verbenaceae) em bovinos. Pesq. Vet. Bras. 19:128-132.

Tokarnia C.H,, Brito M.F., Driemeier D., Costa J.B.D. \& Camargo A.J.B. 1998. Aborto em vacas na intoxicação experimental por pelas favas de Stryphnodendron obovatum (Leg. Mimosoideae) em bovinos. Pesq. Vet. Bras. 18:35-38.

Tokarnia C.H., Döbereiner J. \& Peixoto P.V. 2000. Plantas Tóxicas do Brasil. Editora Helianthus, Rio de janeiro. 320 p.

Traverso S.D., Corrêa AM.R., Pescador C.A., Colodel E.D., Cruz C.E.F.
\& Driemeier D. 2002. Intoxicação experimental por Trema micrantha (Ulmaceae) em caprinos. Pesq. Vet. Bras. 22:141-147.

Traverso S.D., Colodel E.D., Loretti A.P., Corrêa A.M. \& Driemeier D. 2003. Intoxicação natural por Trema micrantha (Ulmaceae) em caprinos. Ciência Rural, Santa Maria, 33:133-136.

Traverso S.D., Corrêa A.M.R., Schmitz M., Colodel M. \& Driemeier D. 2004. Intoxicação por Trema micrantha (Ulmaceae) em bovinos. Pesq. Vet. Bras. 24:211-216.

Vignais P.V., Vignais P.M. \& Stanislas E. 1962. Action of potassium atractylate phosphorylation in mitochondria and in sub-mitochondrial particles. Bioch. Biophys. Acta 66:284-300.

Witte S.T., Osweiler G.D., Stahr H.M. \& Mobley G. 1990. Cocklebur toxicosis in cattle associated with the consumption of Xanthium strumarium. J. Vet. Diagn. Invest. 2:263-267. 